\title{
Design and Construction of the Circular Shape Shaft Using the Reverse Construction Method
}

\author{
Ziqiang Tang* \\ State Grid Fujian Power Economic Research Institute, 350003 Fuzhou, Fujian, China
}

\begin{abstract}
Restricted by the environment and the city's planning, some pipe jacking used for the HV cable tunnel have to pass through some roads which has been build. Different kind of equipment has certain applicability in the pipe jacking construction procedure, especially with the geological condition, and encountering in the boulder is a common problem in the residual soil or in the strong weathered rock stratum, in this situation, a vertical shaft is needed to remove the boulder. In order to save the site area, a new shaft which is in circular shape is designed, and this paper introduces the main procedure of how to design and construct the new circular shaft. In a Fuzhou HV cable tunnel, the new shape shaft clears away the stone in the clay successfully, and reduces the impact on the ground traffic, the design and construction procedure of the new shaft have been analyzed in this paper, which provides reference for similar construction.
\end{abstract}

\section{Introduction}

Slurry balance or earth pressure balance pipe jacking has been widely applied in all kinds of municipal pipe network and small diameter tunnel engineering constructions[1-2]. However, due to the existing cutter is so singleness that it is difficult to adapt to all kinds of formation. When the machine jacking across the composite formation, stagnation frequently occurs because of the underground obstacles encountered[3]. The most common obstacles encountered are weakly weathered solitary stone and backfill construction waste in eluvial soil layer. Because closed-end pipe jacking machines generally do not have the conditions for opening, in this case, the conventional solution is to locate the exact position of the obstacle and get the geometric parameters, use retaining structure of row piles or steel piles after excavation to remove blocks[4]. Because closed-end pipe jacking machines generally do not have the conditions for opening, in this case, the conventional solution is to locate the exact position of the obstacle and get the geometric parameters, the use of retaining structure enclosing row piles or steel piles, excavation after the pit wrecker. Under ambient conditions permit, there is also a caisson troubleshooting well.

Since the purpose is to remove obstacle in front of fiber bundles, so the excavation width is generally the width of drill head. Along the jacking direction, it is likely to be much larger than the head width depending on the scope of the obstacle. Currently, using retaining structure after excavation pit or cast caisson structure and reversed shaft to remove obstacles are more common means, as usual, the shaft is rectangular wells[5].

In terms of current situation, the construction of trenchless technology is most used in municipal roads or other large-scale excavation is not allowed places. Making excavation pit back of retaining structure requires large machinery, larger areas and long period, it's more difficult to implement.

On the other hand, when the well structure is rectangular, the bending moment of long side will be greatly increasing the wall thickness and the amount of reinforcement and lack of economic mobility.

Troubleshooting shafts are also occasionally to be circular wells, sidewall of circular well has good mechanical properties, but as the well is the circumscribed circle of the obstacle, under normal circumstances, it will be a large area, not only the amount of excavation needed will be increased, but also because the cross-section becomes larger, the perimeter of the side wall may bring about the increase of engineering quantity, to a certain extent, the amount of concrete square which is saved by the force performance is offset. At the same time, in the middle of the road facilities for round wells, which covers an area of more than rectangular wells, has a greater impact to road traffic.

A $220 \mathrm{kV}$ high voltage power cable, diameter $3.2 \mathrm{~m}$ concrete tunnel in Fuzhou has been constructed using the pipe jacking, while the tunnel is along the main road, and below the municipal level I road, due encountered a diameter of not less than $1.5 \mathrm{~m}$ solitary stone, the construction had to stop. Through special technology demonstration, they decided to build a continuous wall shaft for troubleshooting. The inner clearance diameter

\footnotetext{
* Corresponding author: tangzq1974@sina.com
} 
of the shaft is $8.0 \mathrm{~m}, 12.0 \mathrm{~m}$ depth. In addition to meet the foundation pit shaft function, it must also set aside the pipe jacking hole of $\Phi 4.1 \mathrm{~m}$ in both sides. Structural design must consider the impact on the integrity of the continuous wall opening. During construction, the tube head should be strictly positioned and in consideration of the consecutive concrete wall's effect, it is difficult to design and construct.

This paper focuses on the above troubleshooting well's function requirements, combined with the technology characteristics of the diaphragm wall, the project design, space layout, structure design, construction monitoring and other related content are introduced, the basis for the similar engineering construction has been provided.

\section{Circular Troubleshooting Shaft Design}

Shaft scheme is restricted by engineering geological conditions, the size of pipe jacking machine, the size and location of obstacles, ambient conditions and other factors. This section describes the circular troubleshooting shaft design briefly.

\subsection{Engineering Geological Conditions}

The pipe jacking zone is monadnock landscape, scattered within alluvial plain geomorphologies, slightly undulating terrain, mainly belongs to Jianxin south road, on both sides of the road are residence and factories. The upper formations of monadnock landscape are artificial landfill, eluvium, the lower cladding layer is granite. Physical and mechanical parameters of soil are shown in Table 1[6].

Table 1.Physical and mechanical parameters of representative soil

\begin{tabular}{|c|c|c|c|}
\hline Soil name & $\gamma\left(\mathrm{kN} / \mathrm{m}^{3}\right)$ & $\begin{array}{c}\mathrm{C} \\
(\mathrm{kPa})\end{array}$ & $\varphi(\mathrm{o})$ \\
\hline (1)Plain fill & 17.5 & 10 & 5 \\
\hline (9)Residual soil & 19.0 & 25 & 20 \\
\hline $\begin{array}{c}\text { (11)Completely } \\
\text { decomposed granite }\end{array}$ & 20.0 & 25 & 35 \\
\hline
\end{tabular}

Variegated brown, loose, slightly wet - wet, mainly composed of gravel, bricks, silty clay, sand, a small amount of garbage and other components, hard impurity content of about $10-40 \%$, poor uniformity, artificial fill.

ranite, pale yellow, brown, can be - hard plastic, wet - slight wet, mainly composed of weathered

out quartz and feldspar, medium dry strength, low toughness, no shaking response, immersion easy to soften.

Pale yellow, the coarse-grained granite structure which is destroyed for dispersion, the main minerals including quartz and feldspar, it is so fragmentary and soft because of intense weathering that can be belong toV grade as Rock basic quality grade.

The main types of underground water along the project site are perched water, pore phreatic water of lower clayey and gravelly sand. The boreholes' stable water depth of monadnock section is about $4.0 \sim 6.0 \mathrm{~m}$, groundwater level is mainly affected by seasonal rains, according to the experience the variation range of water level is about $1 \sim 2 \mathrm{~m}$. The micro confined groundwater's head elevation of lower sand layer is about $0 \mathrm{~m}$.

\subsection{Construction Scheme of Jacking}

A $3.2 \mathrm{~m}$ inner diameter, $2.5 \mathrm{~m}$ long, $0.3 \mathrm{~m}$ thickness precast concrete pipesegment was chosen for the construction, the pipe jacking crossesJianxin north road which is a Class I municipal main road, from the north side to south. In order to avoid the strongly weathered rockwhich may contain boulders, the jacking routewas designed for upward, which is total length of $278.2 \mathrm{~m}$, $7.15 \mathrm{~m}$ elevation difference, the jacking profile is shown in Figure 1.

According to geological formations conditions and the surrounding environmental conditions, the construction company choosesa $\varphi 3.8 \mathrm{~m}$ outer diameter, section of $5.5 \mathrm{~m}$ long full-cutting type pipe jacking machine.

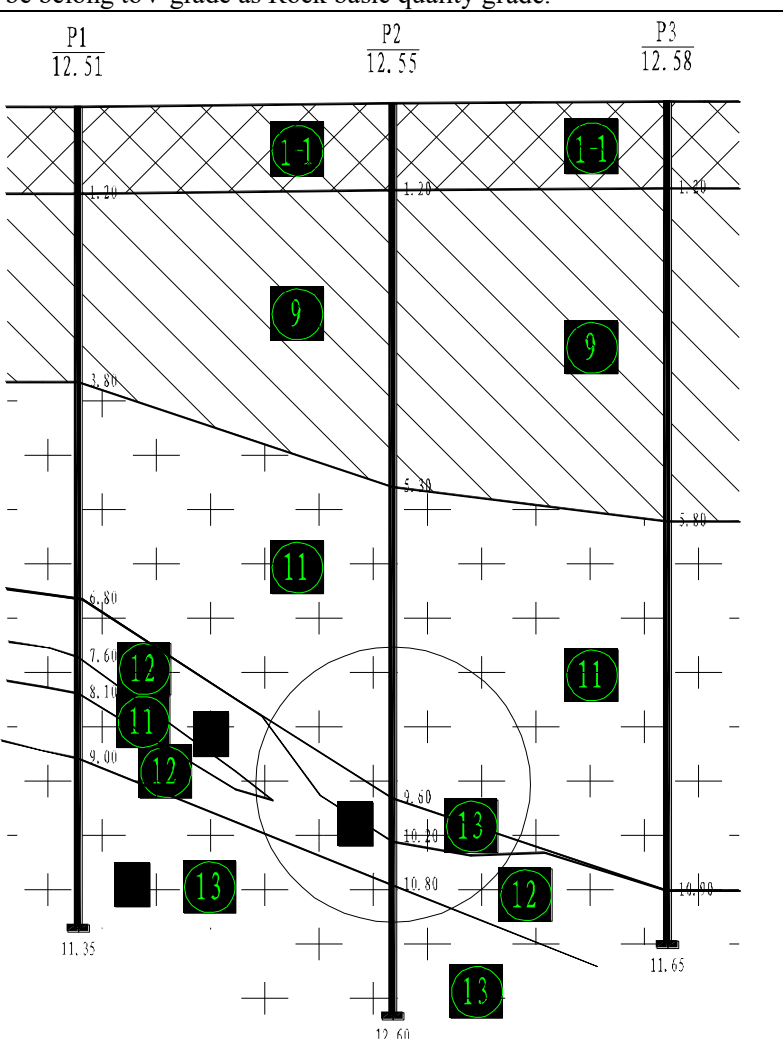

Figure 1. Profile view of jacking 


\subsection{Scheme of Troubleshooting Well}

When the tube to $154.1 \mathrm{~m}$ far away from No.11 well, solitary stone was encountered, pipe jacking equipment was stuck, in order to remove obstacles, thewell No.11 was built. Then jacking started from No. 12 well, when jacking to $54.4 \mathrm{~m}$, there was another stagnation, because of a boulder which is 7.5 meters long along the axis direction of jacking,and not less than 3.8mwidth, foundby $0.5 \mathrm{~m}$ row spacing and $1.9 \mathrm{~m}$ longitudinal spacingadditional survey, the uniaxial compressive strength of the boulder is greater than $100 \mathrm{MPa}$.

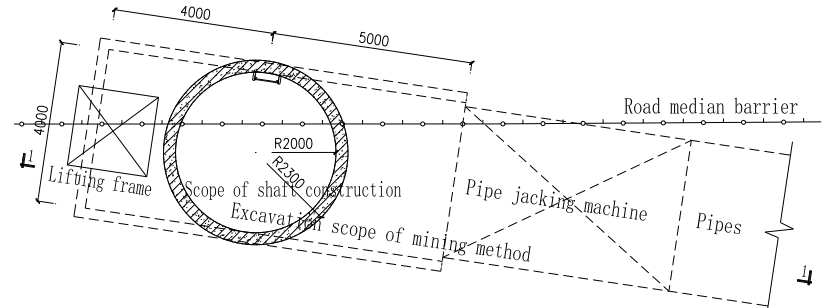

Figure 2. Troubleshooting well floorplan.

In order to clear a boulder, in the case of ground punching can't solve the problem, the construction company decides to add troubleshooting shaft (Project number $11+3$ \#).Because the geological conditions surrounding of shaft mainly are residual soil and weathered rock formation, the groundwater level is deeper, it is suitable for Reversed Construction Method, at the same time, the traffic around shaft is small, ground deformation is not very sensitive, so the shaft is opencut with Reversed Construction Method.

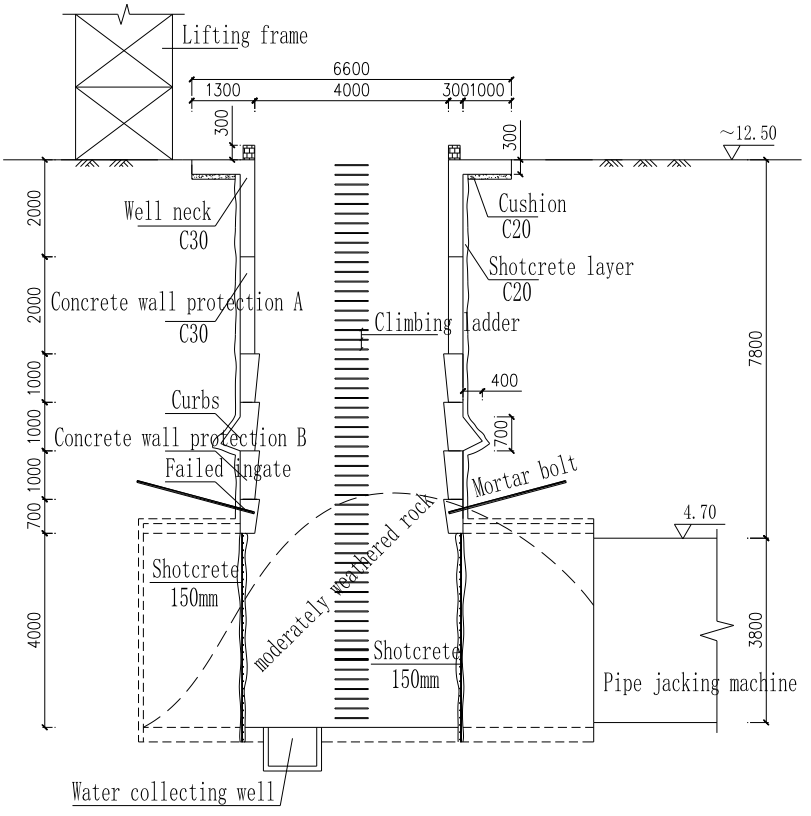

Figure 3. Sectional view of the troubleshooting well and obstacles

According to the information of the obstacles revealed by the geotechnical prospecting, as conventional circular well, the inner clearance dimensions of well is not less than $7.5 \mathrm{~m}$,plus wall thickness and width of ground hanging inverted $\mathrm{L}$ beam. The excavation ground area needed at least $10.0 \mathrm{~m}$, inconsiderationof the construction enclosure occupied area, more than 3 municipal roadsneed to be occupied.

In order to minimize the influence to road traffic, combining the size and location of boulder, the internal diameter is $8.0 \mathrm{~m}$. the shaft layout is shown in Figure 2. Cross-sectional details of the shaft are shown in Figure 3.

\section{Reversed Construction Method of Circular Shaft Design}

Structural design of the shaft includes horizontal and vertical Cross-section direction[7].

\subsection{Design of Horizontal Cross-section}

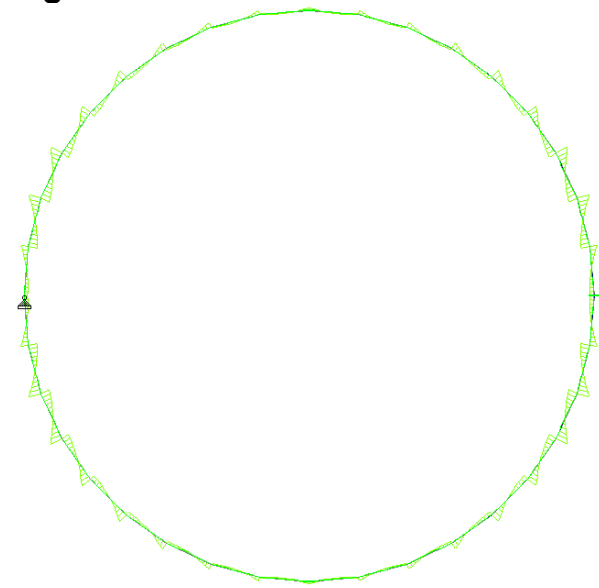

(a) Bending moment diagram

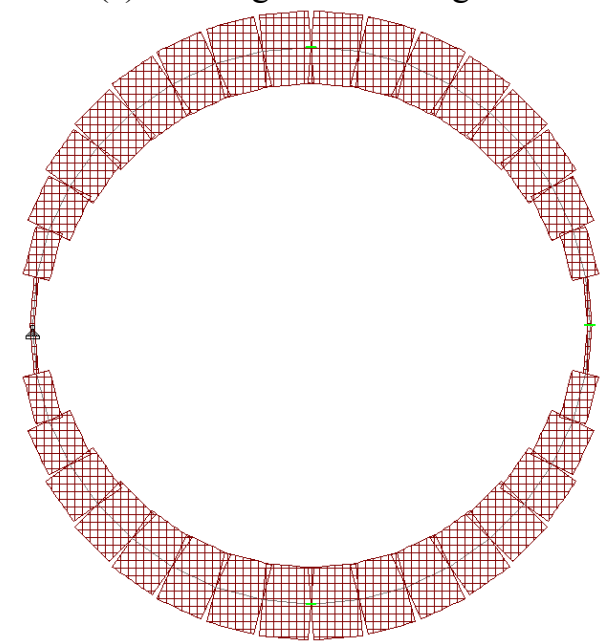

(b) Chart of axial force

Figure 4. Chart of representative internal force

The method of cross-section design follows the tunnel engineering structure, under normal circumstances, load structure method and structure formation method can be used. The load structure method is describedhere:

(1)Along the height direction, combined with lateral earth pressure, a representative cross-sectionis calculated, in general, in height direction, a representative crosssection selecting whose height is $1.0 \mathrm{~m}$ is generally selectedeach 3 4m. 
(2) To calculating the lateral earth pressure in the range of height, assuming that load is uniform distribution around the circular shaft.

(3) Using model of plane strain, the internal force of the $1.0 \mathrm{~m}$ height beam is calculated.

(4)According to the reinforcement method of pure bendingassembly, controlling section is selected for reinforcementwhich decided the lining and outer ring reinforcement of circular wells.

The representative calculation of vertical internal forces of shaft is shown in Figure 4, the long axis direction of outer wall and short axis direction of inner side endure bending load.

\subsection{Vertical Cross-sectional Design of Structure} The vertical structure design mainly consider the selfweight transfer of vertical wall, under normal circumstances, the lower self-weight transferred by vertical rebar, eventually passed on to the ground inverted L-shaped structure, vertical rebar can be configured according to the calculation results. The ground inverted Lshape beams is determined by the bearing capacity of foundation and transfer load, inconsiderationofthe disturbance of soil excavation, a certain safety factor need to be required.

\subsection{Durability and Waterproof Design}

As the shaft is only temporary function well, jacking would continue after troubleshooting. The shaft will be backfilled with sand and restored the pavement structure, so there is no need to consider special waterproofing measures.

\section{Reversed Construction of Circular Shaft}

Reversed construction of circular shaft includes the well collar construction, the side wall excavation, sidewall construction, Ingate construction and surrounding environment monitoring during excavation.

\subsection{Collar Construction of Well}

Well collar construction mainly consists of removing surface Miscellaneous Fill $\rightarrow$ foundation soil compaction $\rightarrow$ rebar binding $\rightarrow$ building the mode $\rightarrow$ pouring concrete $\rightarrow$ pouring the first Section.

\subsection{Well section and Ingate Construction}

Construction of well section actually contains three procedures: excavation of sidewall soil $\rightarrow$ hanging steel mesh and spraying concrete $\rightarrow$ strapping the mode $\rightarrow$ pouring concrete $\rightarrow$ curing concrete to meet the strength requirements $\rightarrow$ excavation of next section. Figure 5 is the pouring construction of collar construction and sidewall situation.

If the shaft connectswith tunnels, the ingate between shafts needspouring construction, which mainlycontains: bolt construction $\rightarrow$ soil excavation of ingate $\rightarrow$ hanging steel mesh and spraying concrete $\rightarrow$ lining construction.

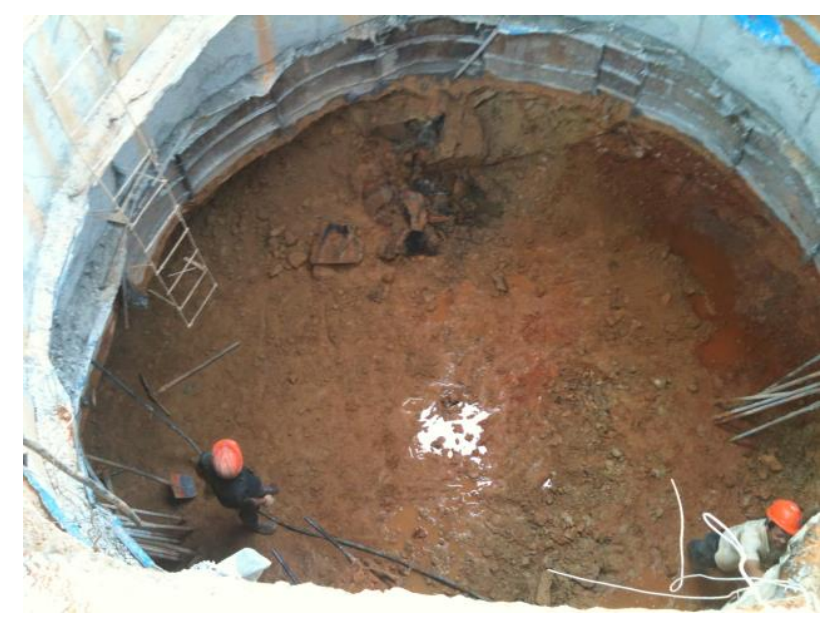

Figure 5.Collar construction and sidewall of circular wells

\subsection{Monitoring of Construction}

Monitoring during shaft construction mainly includes the following aspects: surface deformation monitoring of shaft surroundings which includes surface subsidence and horizontal displacement, monitoring of internal wall convergence deformation. When necessary, steel stress of inner wall and horizontal deformation monitoring will be done.

\section{Conclusions}

The actual project demands as the starting point, a new cross-section form of shaft has been proposed, combined with the actual needs of the project, the design and construction process of the shaft have been described, the conclusions contains:

(1)The footprint of circular shaft is conducive to the engineering construction, and avoids the unloading deformation effect of rectangular wells excavation, at the same time, the wall thickness can be controlled within a certain range. Therefore, it has economic and social benefits.

(2)The circular shaft structure has clear force transmission path and concise design methods, which is easy to spread in relevant projects.

\section{Acknowledgments}

The authors wish to acknowledge. The research is supported by State Grid Fujian electric power CO., LTD.

\section{References}

1. Chen Xiaozheng, Zhang Peiyong, Ding Shijun. Analysis of jacking force estimation and measurement for large-caliber three-dimensional curved jacking[J]. Rock and Soil Mechanics, 2015, 36 (Suppl 1): 547-552. (in Chinese)

2. People's Republic of China Ministry of Urban and Rural Construction. Construction and Acceptance 
Specification of drainage GB 50268-2008 in [S]. Beijing: China Building Industry Press, 2008.

3. Shanghai Municipal Engineering Design Institute CECS 246: Pipe Jacking Technical specification of Water Supply and Drainage,2008 [S] Beijing: China Planning Press, 2008.

4. Tan Jianfeng. Processing method of large boulder in pipe jacking $[\mathrm{J}]$. China Science and Technology Information, 2007, (10): 52, 54. (in Chinese)

5. WEI Gang, ZHU Kui. ANALYSIS OF ADDITIONGAL LOAD ON ADJACENT UNDERGROUND PIPELINE INDUCED BY JACKING CONSTRUCTION[J]. Chinese Journal of Rock Mechanics and Engineering, 2007,26(Supp.1):2724-2729.(in Chinese)

6. Xiao Shixiang, Chen Meiluo, Chen Dongqian. The geological evaluation report of Jianxin to Xiannong 220kV HV line engineering [R]. Fuzhou: Fujian Electric Power Survey \& Design Institute, 2010.(in Chinese)

7. Zhao Chao, Peng Xiaolin. Processing Technology of solitary stone in electricity tunnel[J]. Guangdong Civil Engineering and Architecture, 2012, (10): 6062. (in Chinese) 